\section{SOME POINTS IN THE PHYSICS OF GOLF.}

II.

I N my former paper (Nature, Aug. 28, I 890) the main conclusions were based to a great extent upon the results of mere eye observations, often of a very uncertain and puzzling kind. The data so obtained were unfortunately not those required for a direct investigation, so that my processes were necessarily of a tentative character. During and since the last College session I have been endeavouring to obtain some of the more important data in a direct manner. I am thus in a somewhat more favourable position than before but, as will soon appear, the new information I have obtained has complicated rather than simplified the singular problem of the flight of a golf-ball.

One point, however, which is both curious and important, has been clearly made out:--hammering has no effect (or, to speak more correctly, only an inconsiderable effect) on the coefficient of restitution of a golf-ball. This conclusion, which may have to be modified if the striking surface be not plane, had for some time appeared to me as almost certainly correct, and I have recently verified it by means of the Impact apparatus with which I have been working for some years. I procured from St. Andrews a number of balls of the same material and make, half of them only being hammered, the others plain. The results obtained from a hammered, and from an unhammered, ball did not differ much more from one another than did those of a number of successive impacts on one and the same ball. In the Badminton Library volume on Golf, Mr. Hutchinson quotes a statement of mine which appears at first sight diametrically opposed to this experimental result; and thus puts me in the position de nier ce qui est et d'expliquer ce qui n'est pas. But he has omitted to mention that my statement was expressly based on the allegation that a hammered ball had been definitely found to acquire greater speed than an unhammered one. This seemed to me even at the time very doubtful, and I now know that it is incorrect.] Thus it is clear that the undoubtedly beneficial effects of hammering must be explained in some totally different way. There is another, and even more direct, mode of arriving at the same conclusion. To this I proceed, but unfortunately the new point of view introduces difficulties in comparison with which all that has hitherto been attempted is mere child's play. In short, it will be seen that the problem of a golfball's flight is one of very serious difficulty.

In my former article 1 took no account of the rotation of the ball, treating the problem in fact as a case of the motion of a particle in a medium resisting as the square of the speed. The solution I then gave was only approximate, and limited by the assumption that the cosine of the inclination of the path to the horizon might be treated as unity throughout. The illustrations and extensions given were founded on the same basis as was the solution of the simpler problem. Shortly after it was published I made, by the help of Bashforth's tables, a more exact determination. The data $I$ thus arrived at were (in Bashforth's notation)

$$
\lambda=r^{\circ} 9, \quad u_{0}={ }_{1} 3 \mathrm{r} \text { feet-seconds, } \phi=13^{\circ} 5 .
$$

From these the tables give at once

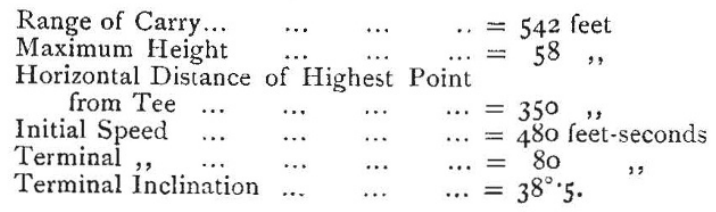

As a contrast, take $\lambda=\mathrm{I} \cdot \mathrm{I}$, so that $u_{0}=\mathrm{I} 00$ feetseconds. To obtain the observed range we must take NO. I I 43 , VOL. 44$]$ $\phi=23^{\circ} \cdot 25$, which is considerably too great. The other numbers then become

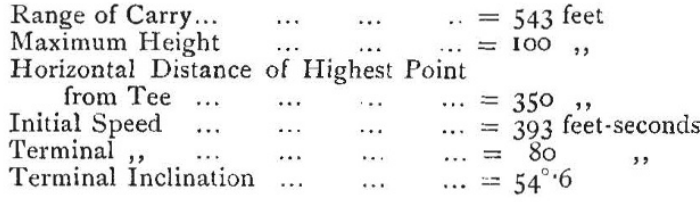

The first numbers are in remarkable accordance with the numerical details of really good drives which I obtained from Mr. Hodge; and, were there no other crucial test to be satisfied, the problem might have been regarded as solved to at least a first approximation. But I felt very suspicious of the sufficiency of such a solution; especially as it made no place (as it were) for the possibility of a path in part straight, or even occasionally concave upwards, which I have certainly seen in many of the very best drives. And my doubts were fully justified when I calculated from Bashforth's tables the time of flight under the above conditions. For they give $\mathrm{I} \cdot 5 \mathrm{IS}$ for the first, and $2 \cdot 13 \mathrm{~s}$. for the second, part of the path:$3^{\circ} 6$ seconds in all ; while the observed time of flight in a really good drive is always over 6 seconds, and sometimes quite as much as 7 . This I have recently verified for myself with great care in the competition for the Victoria Jubilee Cup, where one of the unsuccessful players distinguished himself by really magnificent driving. The time of flight in the second of the above forms of path is about 4.8 seconds.

The initial speed in the first estimate seems to be excessive, as will appear from the experiments to be described below. This, of course, is one mode of explaining how the time of flight is so much underrated. But, if we keep to Bashforth's value of the coefficient of resistance, it is impossible to reduce the initial speed (while preserving the observed range) without increasing the angle of projection and, with it, the greatest height reached. The second set of numbers conclusively proves this. On the other hand if, with the view of reducing the initial speed and thus increasing the time of flight, we assume a smaller resistance, we may keep range, height, and initial angle, nearly as observed; but we shift the vertex of the path unduly towards the midrange. The only way, it would therefore seem, of reconciling the results of calculation with the observed data, is to assume that for some reason the effects of gravity are at least partially counteracted. This, in still air, can only be a rotation due to undercutting.

During last winter I made a considerable number of experiments with the view of determining the initial speed by the help of a ballistic pendulum, but the results of these cannot be regarded as very satisfactory. My pendulum was a species of stiff but light lattice-girder constructed of thin, broadish, laths. This hung from hard steel knife-edges set well apart, and supported a mass of moist clay of about roo lbs. 'The clay was plastered into a nearly cubical wooden frame, and swung just clear of the floor. The ball was driven into it from a distance of about six feet, and as near as possible to the centre of one face. The effective length of the corresponding simple pendulum was about $10 \mathrm{feet}$, and the utmost deflection obtained (measured on the floor) was about two inches. From these data I deduced an initial speed of about 300 feet per second only. But the experiments were never quite satisfactory, as the player (however skilful) could not free himself entirely from apprehension of the consequences of an ill-directed drive. In fact, several rather unpleasant accidents occurred during the trials, especially in the earlier stages; when the pendulum was mounted in a stone cellar, and without the hangings and the paddings which were employed in the later work. Although the clay was so stiff as to 
preserve its form under gravity, the ball (when it struck the face near the centre) always penetrated to a depth of more than one diameter, and splashed fragments of the clay to a considerable distance. These were usually replaced, and the surface levelled for a fresh experiment, as soon as the ball was dug out. The speed of 300 feet per second, thus measured, may be taken as an inferior limit to the initial speed in a really fine drive.

It thus appears that the resources of mere particle dynamics are quite insufficient for the adequate solution of the problem of long driving; though, of course, they fully meet all questions connected with mere approach shots ; and that the rotation of the ball must play at least as essential a part in the grandest feature of the game, as it has long been known to do in those most distressing peculiarities called heeling, toeing, slicing, \&c. But when this is once recognized, it is only the beginning of sorrows; for even the approximate treatment of the eddies produced by the rotation appears to be at present beyond our powers.

In order that the path of the ball may be (for a short time) approximately straight, still more if it is to be concave upwards, the downward acceleration due to gravity must be neutralized by the effects of a rotation due to undercutting. [Of course enormous speed could produce the approximately straight path, but not the concavity.] Hence the necessity for a tee, unless the turf be exceptionally soft, in order that the club may impinge on the lower part of the ball. Hence also one important use of hammering, viz. that the undercut ball may take as much angular velocity as possible:- the other being that the spin, so acquired, may tell as much as possible during the flight. The gist of the matter is thus seen to be :--For steady flight the ball must have rotation of some kind. The best mode, that of a rifle-ball, is of course unattainable. The others produce respectively heeling, toeing, dooking, and soaring. Of these the last, alone, is not necessarily disastrous; and it is therefore to be adopted.

I have not hitherto succeeded in my attempts to apply even approximate calculation to this altered set of conditions :- but it is easy to see, without calculation, that the longer the path of the ball retains nearly its initial inclination to the horizon (even if, in achieving this, it should have to expend part of its energy of translation along with that of rotation, and thus diminish the range) the longer will be the time of its flight during the carry.

And, as a practical deduction from these principles, it would appear that to secure the longest possible carry the ball should be struck so as to take on considerable spin:-so that the ideal driver should be in truth a Bulger, but with the important variation that its bulge should be of considerable curvature and in a vertical, not a horizontal plane. The height of the most prominent part of the face (above the horn) must of course be less than the radius of the ball How much less can be found only by trial. And, in addressing the ball, the player must stand directly opposite to it. Such clubs, however, could be profitably used only by really good players:men who can hit with what part of the club they please. The reckless swipers of the present generation, who slash away anyhow, and (with ordinary clubs) manage occasionally to make a really "tall" drive, will probably smash the proposed form of club on the very first appearance of topping. As to those who propel the ball by "skittling" rather than driving, any change must be an improvement, so that they should welcome the proposed novelty. The matter is a very simple one. A few touches skilfully applied with a rough file, and the new system rises at once out of the old.

There is one other point on which opinion seems to be so unsettled that an allusion may be made to it here :the effects of weather on the carry of a ball. Of course, other circumstances being the same, the only direct effect is on the coefficient of resistance. If this be taken as proportional (roughly) to the density of the air, it may vary, in this climate, to somewhere about ten per cent. of its average amount, by increase or by diminution. It has its greatest value, and the drive is accordingly shortest, on a dry cold winter day with an exceptionally high barometer. The longest drive will of course be when the air is as warm and moist as possible and the barometer very low.

P. G. TAIT.

\section{HOOKER"S "ICONES PLANTARU.Y."}

THE recent issue of the fourth part of vol. xx. of the entire work completes the volume, and closes the third series, with a total of two thousand plates. This useful, and now indispensable, publication was commenced by the late Sir William Hooker in 1837, and the first volume was dedicated to the late George Bentham, who is described in the dedication as an "ardent promoter, not less by his patronage than by his writings, of botany and horticulture." Sir William Hooker started the "Icones" to illustrate some of the numerous novelties in the collections which were pouring into his herbarium from various parts of the world, especially from the southern hemisphere, at that period. With a few exceptions by Harvey, Gardner, and others, the drawings and descriptions were by Hooker himself, and a volume, containing one hundred plates, appeared annually, or nearly so. The first series closed with the fourth volume in I84I. At this date the founder was already Director of Kew Gardens, and he continued the work to the tenth volume, which terminated the second series. Two or three of the later volumes of this series were illustrated by the then rising botanical artist, W. H. Fitch. In the tenth volume we find a dedication of the whole ten volumes to George Bentham, in much the same words as the first. This was in 1854. After an interval of thirteen years, the third series was commenced, under the editorship of Dr. J. D. (now Sir Joseph) Hooker; and G. Bentham, D. Oliver, and J. G. Baker were contributors. Mr. Bentham, we believe, financed the undertaking. This, the eleventh volume, was not completed until $187 \mathrm{I}$; but it is a most interesting volume, illustrated by Fitch, and containing among other things many of the endemic plants of St. Helena. The second volume of this series, the twelfth of the whole, was also illustrated by Fitch, and is valuable for the figures of curious new genera founded by Bentham and Hooker when elaborating their "Genera Plantarum."

On the completion of this volume, in 1876 , a difficulty arose, consequent on the retirement of the artist, though there was no actual interruption in the appearance of the parts. But it was impossible to replace an artist like Fitch. Indeed, the only alternative was to train a person to do the work. This was not so easily accomplished; there were failures, and so high a standard of excellence has not since been reached. Nevertheless, the present artist gives as good drawings as could be expected from dried, flat specimens, and the botanical details are usually as full as is necessary, if not all that could be desired.

Since Mr. Bentham's death, in 1884, the work has proceeded with greater rapidity, and is now appearing at the rate of a volume per year. It is now published at the expense of the Bentham Trustees, ${ }^{1}$ and sold at about half the former price; and since his retirement Prof. D. Oliver has undertaken the editorship. Under such favourable auspices, together with the abundance of material in the Kew Herbarium, it is confidently hoped that the interesting character of the work will be fully maintained, and that the mechanical production of it will be improved, resulting in a larger sale. The later volumes

${ }^{1}$ Of a fund beqreathed by Bentham for the advancement of Lotanical science. 